\title{
Teknokultura
}

ISSN: $1549-2230$

\section{La cultura del impacto en la universidad española y la privatización del conocimiento público}

\author{
Enrique Javier Diez Gutiérrez ${ }^{1}$
}

Recibido: 30 de noviembre de 2016 / Aceptado: 10 de marzo de 2017

Resumen. La comunidad científica en nuestro país está sufriendo grandes presiones para transformar la investigación rigurosa en una loca carrera de la "cultura del impacto y de la citación" para ser valorado y poder promocionar. El motivo fundamental es que este sistema ha asumido la tesis de que el factor de impacto (media de citas que en un año tiene un artículo) defina el valor científico de artículos y revistas.

Palabras clave. Comunidad científica, investigación, índice de impacto, docencia

\section{[en] The impact culture in the Spanish university and the privatization of public knowledge}

\begin{abstract}
The scientific community in our country is suffering great pressure to transform rigorous research into a mad race of "impact culture and citation" in order to be valued and promoted. The fundamental reason is that this system has assumed the thesis that the impact factor (paper's citations average per year) defines the scientific value of articles and journals.
\end{abstract}

Keywords: Scientific community, research, impact factor, teaching

Sumario. 1. Decisiones políticas. 2. Críticas del sistema de evaluación. 3. La esencial función docente de la Universidad se devalúa. 4. Otro sistema de evaluación es posible, y necesario. 5. Referencias bibliográficas

Cómo citar: Diez Gutiérrez, E. J. (2017) La cultura del impacto en la universidad española y la privatización del conocimiento público. Teknokultura 14, 163-169.

1 Universidad de León

Email: enrique.diez@unileon.es 
El acceso a la función docente e investigadora universitaria en España se ha implementado mediante un sistema de acreditación no pública ante una agencia de evaluación, la Agencia Nacional de Evaluación de la Calidad y Acreditación (ANECA) o las autonómicas para categorías no funcionariales.

Este sistema ha generado un modelo basado en la acumulación constante de "méritos" por parte del profesorado universitario para poder acceder a los puestos solicitados. En efecto, los criterios establecidos por las agencias de evaluación han lanzado al profesorado universitario a un interminable proceso de búsqueda continuada de la acreditación por escrito del más mínimo mérito, de la publicación en revistas determinadas, elegidas sólo por su posición en los distintos índices y rankings de impacto, aunque su relevancia o utilidad social sea muy cuestionable, o de la multiplicación de tareas de gestión "acreditable". Todo ello a los solos efectos de conseguir acumular los ítems necesarios para cumplir con las exigencias ANECA, independientemente de su utilidad para la formación académica o mejora real de la calidad de la docencia.

El conjunto del engranaje se acciona desde las agencias nacionales de evaluación, fundamentalmente la Agencia Nacional de Evaluación de la Calidad y Acreditación (ANECA) y la Comisión Nacional de Evaluación de la Actividad Investigadora (CNEAI). La primera acredita la capacidad del profesorado, la segunda reconoce la actividad investigadora realizada a través de los sexenios.

Los denominados “sexenios" se consagraron con el Real Decreto 1086/1989, de 28 de agosto de 1989, sobre retribuciones del profesorado universitario, que "premiaba" con un aumento de sueldo a quienes durante el último período de 6 años (sexenio) hubieran publicado al menos cinco artículos en revistas científicas incluidas en las bases de datos elaboradas por dos multinacionales Thomson Reuters y Elsevier. Actualmente la ANECA y la CENEAI priorizan como criterios de valor, para acreditarse y conceder esos sexenios, la publicación de artículos, en detrimento de otros formatos y modos de canalizar la actividad investigadora.

Este sistema de evaluación se centra en medir el factor de impacto, concebido en 1963 por Eugene Garfield e Irving Sher a través del recuento del número de citas que ha obtenido un artículo en un período concreto de tiempo (Túñez, 2013). Se asume, pues, la tesis de que el factor de impacto defina el valor científico de artículos y revistas. El factor de impacto se controla a través de los datos ofrecidos por dos multinacionales: Thomson Reuters y Elsevier, a través de sus productos Web of Science (WoS), en el que se incluye el informe Journal of Citation Report (JCR) y Scopus, respectivamente. Ambas ofrecen un ranking de clasificación de las revistas más citadas, y por tanto más "prestigiosas” y valoradas a la hora de ser acreditado cualquier profesional en el ámbito de la Educación Superior.

De esta forma, la valoración de buena parte de la labor profesional del profesorado universitario, al menos la que permitía obtener más reconocimiento y prestigio, se centró en la publicación en revistas que estuvieran en lo alto del ranking establecido por esas dos multinacionales fundamentalmente. Surgió así una floreciente "industria de la acreditación", con un corpus de personal experto en los arcanos de la justificación de méritos que se ofrecen a orientar, previo pago, sobre la mejor manera de "colocar" artículos en las revistas de mayor impacto de esas bases. El problema añadido además es que ese factor mide en mayor medida la visibilidad que la calidad. 
Este modelo neoliberal hacia el que se avanza, que fija retribuciones, dedicación y prestigio en función de los resultados, supone un aumento de la presión y del estrés laboral, del ritmo de trabajo y una modificación de las relaciones sociales y profesionales (Ball y Youdell, 2007), lo cual produce malestar y aliena el trabajo docente (Támez \& Pérez, 2009).

Aprovechando la demanda de transparencia y responsabilidad profesional que se le exige a cualquier institución pública y a los profesionales que la integran, ha reducido esta necesidad a una visión estrecha de lo que tradicionalmente se ha entendido en el mundo empresarial como "rendición de cuentas", accountability, expresada en términos de rendimientos, rentabilidad o impacto de las producciones realizadas. De esta forma se ha desarrollado un culto a las mediciones y controles que ha convertido la "rendición de cuentas" en indicadores estandarizados "sencillos”, en mediciones de resultados y puntuaciones. Introduce así la lógica del capital incluso dentro de propia subjetividad de los integrantes de la academia.

El problema no radica en que se evalúe la labor docente e investigadora del profesorado. El problema, para una universidad que pretenda formar ciudadanía y no solo meros profesionales cualificados, crear pensamiento crítico y realizar investigación de calidad, se encuentra en el enfoque y los criterios que se manejan para realizar estas evaluaciones. Es cuestionable, en cuanto a los criterios, por ejemplo, que la cuantificación de publicaciones en revistas "de alto impacto" gestionadas en la mayoría de los casos por empresa privadas, frecuentemente anglosajonas, con procedimientos, como poco, oscurantistas y sobre la base de intereses comerciales y de negocio rentable.

Montenegro y Pujol (2013) se preguntan ¿cómo es posible que se haya convencido a los Estados de que la mejor producción científica es aquella que se difunde en un idioma ajeno al país y valorada por personas que desconocen el contexto al cual ese conocimiento puede ser potencialmente aplicado? Si éste hubiera sido el razonamiento desde hace siglos, indudablemente habríamos acabado con la historia del pensamiento occidental, con toda perspectiva heterodoxa y con cualquier objeto de estudio que a priori pueda considerarse marginal. Albert Einstein no hubiera recibido ni un punto en nuestra agencia evaluadora por su opúsculo sobre la Teoría de la Relatividad que marcó el cambio de la física mecánica a la física cuántica.

Como podemos comprobar, pues, la comunidad científica en nuestro país está sufriendo grandes presiones para transformar la investigación rigurosa en una loca carrera de la "cultura del impacto y de la citación" para ser valorado y poder promocionar. La comunidad universitaria se siente impelida a trabajar por el impacto y el reconocimiento, sin importar mucho el verdadero significado de esos índices y estándares (Third Person, 2012). La finalidad ya no es tanto la calidad como una buena situación en el ranking de esos índices de citación, aún a sabiendas de que no hay una correlación total entre ambas (Herrán, 2012; Scott, 2013).

\section{Decisiones políticas}

Las multinacionales Thomson Reuters y Elsevier, reciben por sus productos Web of Science (WoS) y Scopus respectivamente, más de 25 millones de euros como pago por las licencias de utilización de dichas bases de datos, por parte de la Fundación 
Española para la Ciencias y la Tecnología (Giménez-Toledo, 2013; Túñez y De Pablos, 2013), dependiente del Ministerio de Economía y Competitividad, las Universidades y el Consejo Superior de Investigaciones Científicas (CSIC).

Al mismo tiempo, desde 2013 se paralizaban por recortes presupuestarios proyectos públicos de prestigio encargados de evaluar la calidad de las revistas científico académicas españolas. El sistema DICE (Difusión y Calidad Editorial de las Revistas Españolas de Humanidades y Ciencias Sociales y Jurídicas) se había desarrollado desde 2006 por el CSIC. No recibía dinero de las revistas que estudiaba y catalogaba, ni tampoco directamente de quienes lo consultaban. INRECS, INRECJ e INRECH (Índice de impacto de las revistas españolas de ciencias sociales, jurídicas y humanidades) de la Universidad de Granada sufrieron la misma suerte en el año 2014.

De esta forma, nuestras administraciones públicas cooperan en la financiación y difusión de las multinacionales privadas extranjeras para el desarrollo de su sistema comercial de evaluación. Los ministerios de Ciencia y Tecnología le atribuyen la autoridad y el liderazgo que estas multinacionales se autoatribuyen en sus páginas web, desde su "monopolio de hecho" de la evaluación científica.

Es más, en España se da la paradoja de que se promociona con claridad la publicación en abierto, de acuerdo con la Ley 14/2011, de 1 de junio, de la Ciencia, la Tecnología y la Innovación, pero a la hora de evaluar la actividad científica, las agencias valoran especialmente las revistas cubiertas por la Web of Science (Thomson Reuters) o por Scopus (Elsevier). Es decir, se admite el valor de la publicación en abierto y accesible a todo el mundo para difundir la investigación, pero no se reconoce su valor científico en los procesos de evaluación, excepto si es una revista en abierto que está incluida en WoS (Giménez-Toledo, 2014). Lo cual dota de una inmensa influencia a estas dos grandes corporaciones sobre la política científica de nuestro país.

\section{Críticas del sistema de evaluación}

Este sistema ha recibido innumerables críticas, puesto que presenta un enorme sesgo lingüístico y geográfico que favorece a publicaciones y autores y autoras anglosajones hasta que enfatiza estándares determinados de ciencia. Estos criterios de valor, además, reproducen una lógica colonial pues refuerzan una lógica geopolítica de poder que margina y desprecia las revistas científicas no anglosajonas, imponiendo sin discusión el inglés como lengua "neutra".

También se ha criticado la recurrencia y la permanencia de los círculos científicos dominantes que se nutren y se citan entre sí (de las más de 8.000 revistas de todo el mundo que son incluidas en el JCR, tan solo 300 representaron más del $50 \%$ de lo que se citó y más del 30\% de lo que se publicó; y un núcleo de 3.000 revistas cuenta con más del 90\% de artículos citados y más del 80\% de los publicados). Asimismo, se ha enfatizado el escándalo que supone el hecho de que resultados de investigaciones pagadas con dinero público se publiquen en revistas de acceso privado.

Se cuestiona que estos sistemas privados se conceptúen a sí mismos como depositarios de la calidad (Herrán, 2012). Se insiste en que incrementen el "efecto 
Mateo”, según el cual unos pocos son muy citados y la inmensa mayoría caen en el olvido: la mayor parte de las publicaciones pasan sin dejar ningún rastro; no se las cita en absoluto, ¡ni siquiera una sola vez!, y el 80 por ciento solo se citan una vez (Scott, 2013).

Lo cierto es que con este modelo la producción de conocimiento se encierra en un circuito privatizado, ajeno en buena parte a su servicio a toda la sociedad y al compromiso con el bien común. A pesar de las críticas de todo tipo que este modelo ha generado, conserva intacta su capacidad de definir quién vale y quién no. Se asume así que aquello que ocurre fuera de lo validado por el modelo no existe o no sirve a la ciencia: "si tu trabajo no está aquí, no vale".

El problema que incrementa este modelo es que para acceder a un puesto en el ámbito universitario, acreditarse para cualquier puesto docente, promocionar en la carrera académica, cobrar el complemento de investigación o simplemente no verse "cargado" con más horas de docencia, todo profesor o profesora universitaria se ve obligado, de una u otra forma, a conseguir que esas dos multinacionales le admitan publicar cierto número de artículos en las revistas que ellas determinan y controlan, entrando así en esta competición constante.

Esta bibliometría, más que aportar resultados de investigación excelentes, ha conseguido presionar a la comunidad investigadora para adaptar su trabajo hacia lo que se valora en el mercado de los sexenios. Se abandonan las monografías o libros con conocimiento reflexivo de fondo capaces de alcanzar al gran público, pues son consideradas "méritos menores" porque puntúan menos frente a los artículos con índices medibles de impacto.

Se está generando así una inflación de papers inabarcable, que pocos leen y que no siempre se escriben con el poso necesario. Se recurre al autoplagio, a las autocitas, a las redes de citas, a las guerras de citas, a no citar a posibles competidores/as, a exigencias de citar artículos publicados en los últimos años en la revista donde se quiere publicar. Se produce un volumen innecesario de aparato de citación, un hipertrofiado marco teórico, postizo y muchas veces ni siquiera consultado, que solo sirve para aumentar este mercado de la citación, cuestionado en innumerables investigaciones y estudios.

Todo ello obliga a un proceso continuo de competición interna que fragmenta y enfrenta al profesorado, naturalizando la competencia en vez de producir formas colaborativas de pensamiento e investigación.

Lo que vale, lo que cuenta, lo que tiene valor (de mercado) es la acumulación, lo inmediatamente vendible y comercializable en el mercado de la patente y la industria del rápido beneficio, no la investigación base ni la dimensión crítica de la investigación.

\section{La esencial función docente de la Universidad se devalúa}

Este sistema de evaluación de la carrera profesional universitaria, sobre todo a partir del Real Decreto-ley 14/2012 del PP, que premia la acumulación de esas publicaciones cuantificables y comercializables que son las que supuestamente generan "distinción y reconocimiento" (sexenios), al mismo tiempo "penaliza” si no se 
consiguen, con la imposibilidad del acceso, la no promoción, la reducción del salario y un aumento significativo de carga docente.

La función docente esencial de la universidad se ha convertido así en un obstáculo para la promoción académica, un "castigo", que termina por devaluar la finalidad fundamental de la universidad, provocando que el mismo profesorado la minusvalore y postergue. Sabiendo, además, que no está probado -más bien al contrario- que haya una correlación importante entre productividad de la investigaciónpublicación y eficacia de la docencia.

Frente a la docencia, la práctica investigadora es transformada en una inversión en el propio currículum mediante este tipo de publicaciones que sí reportan beneficios subjetivos (valoración) y materiales (compensaciones retributivas). Este sistema valora aquellas publicaciones que tengan valor para el mercado y que se puedan cuantificar y medir. Olvida que la ciencia debe estar al servicio de la humanidad y de la mejora del mundo en el que convivimos, ligada a problemas y necesidades sociales que no siempre son valorados por el mercado, para convertirse en una moneda de cambio determinada por las exigencias del mercado.

\section{Otro sistema de evaluación es posible, y necesario}

Necesitamos una universidad realmente pública y democrática. Una universidad que cuestione esta concepción neoliberal de la ciencia, la investigación y la docencia en educación superior. Que ponga en jaque el significado otorgado a la "excelencia", entendida como incentivo para que se aumente de manera constante, competitiva e ilimitada la productividad.

Es necesario apostar por una universidad que sea capaz de incorporar otros elementos de valor al trabajo investigador y docente: trabajo compartido, investigación de base y a largo plazo, docencia como responsabilidad esencial, honestidad científica, compromiso con toda la sociedad y también con las necesidades y sectores más desfavorecidos.

El mérito medido cuantitativamente y el sistema de auditores numéricos "objetivos" para evaluar la calidad sustituye un necesario debate democrático sobre la política de las disciplinas respecto a los criterios de valor y de conocimiento para ponerla en manos de cálculos pseudocientífico supuestamente "neutrales".

Los países que tienen un enfoque de modelo social y productivo de alto valor son aquellos que cuentan con más apoyos a la investigación básica y en todas las disciplinas, también las humanísticas, sociales y artísticas. No en vano dicha investigación es la que genera los cimientos para construir un modelo social más justo en lo económico, más sabio en lo social y más ecológico en lo natural. Son aquellos que valoran también el impacto social y político de la investigación no sólo por el número de citas de las publicaciones realizadas sino por la implicación en la resolución de problemas locales o en el avance del bienestar social, por la participación de la comunidad en el desarrollo de las investigaciones o porque incluyen orientaciones prácticas para la solución de problemas reales en contextos reales, sean locales o globales.

Es necesario superar las métricas basadas en el factor de impacto de las citas en JCR y similares, que miden el continente más que el contenido, ahorrar al Estado 
una ingente cantidad de dinero que pagamos a estas multinacionales extranjeras y sentar las bases para que la academia dé a luz un nuevo sistema de evaluación público y abierto de la investigación.

En definitiva, los repositorios públicos de “acceso abierto”, mandato expreso del programa de la Unión Europea Horizonte 2020, en la línea que plantea la Declaración de San Francisco sobre Evaluación de la Investigación (DORA) y la Declaración de Berlín, administrados por universidades u organizaciones de investigación públicas, son una valiosa infraestructura que podrían apoyar la transición a un sistema de evaluación y comunicación académica más colaborativa y eficiente.

Es urgente dar pasos hacia otro sistema posible de evaluación de la producción científica más justo, que responda a un modelo de ciencia para el bien común.

\section{Referencias bibliográficas}

Ball, S., \& Youdell, D. (2007, July). Privatización encubierta en la educación pública. Informe preliminar. In V Congreso Mundial.

Giménez Toledo, E. (2014). Imposturas en el ecosistema de la publicación científica. Revista de Investigación educativa, 32(1), 13-23.

Giménez-Toledo, E. (2012). Revistas científicas en 2012: trilogía para la reflexión y la acción. El Profesional de la Información-Notas ThinkEPI, 2013, 1-4.

Herrán, A., \& Villena, J. L. (2012). Algunas Críticas a la Evaluación del Profesorado Universitario Centrada en el Impacto. A. de la Herrán \& J. Paredes (Coords.), Promover el cambio pedagógico en la universidad. Madrid: Pirámide.

Montenegro Martínez, M., \& Tarrès, J. P. (2013). La fábrica de conocimientos: in/corporación del capitalismo cognitivo en el contexto universitario. Athenea digital, 13(1), 139-154.

Scott, J. C. (2013). Elogio del anarquismo. Grupo Planeta (GBS).

Támez González, S., \& Domínguez, J. F. P. (2009). El trabajador universitario: entre el malestar y la lucha. Educ. Soc, 30(107), 373-87.

THIRD PERSON (2012). Neoliberalismo en la Universidad Metropolitana de Manchester... y una alternativa. Revista Teknokultura, 9(2), 337-346..

Túñez, M. (2013). The'h-index'in Communication research in Spain, Portugal and Latin America: Web of Knowledge (WoK), Scopus and Google Scholar Metrics. Communication \& Society, 26(4), 53-75.

Túñez, M., \& Pablos, J. M. D. (2013). El” índice h” en las estrategias de visibilidad, posicionamiento y medición de impacto de artículos y revistas de investigación. Actas del II Congreso Nacional sobre Metodología de la Investigación en Comunicación y del Simposio Internacional sobre Política Científica en Comunicación (133-150). Segovia: Universidad de Valladolid. http://uvadoc.uva.es/handle/10324/2996. 